\title{
DETERMINATION OF CROSS SECTIONS FOR GRAVITY TYPE QUAY WALLS
}

\author{
Z. Tugce Yuksel'; Yalcin Yuksel²; Busra Basaran² and Esin Cevik²
}

Block type quay walls are widely used as port structures in the world. In this study three types of vertical block type quay walls with different block size exposed to seismic loading were investigated experimentally. The block ratios of Type I, Type II and III vertical wall models are $\mathrm{B} / \mathrm{h}=2,1.5$ and $1.5 \& \mathrm{H} / \mathrm{h}=6,6$ and 3 , respectively. The tests were conducted in the shaking tank with different harmonic seismic loadings and the behaviors of these walls were investigated comparatively.

Keywords: Block type structure; quay wall; seismic behavior; shaking tank

\section{INTRODUCTION}

Coastal and port structures are not only subjected to waves but can also be exposed to seismic forces. When the damages of the port structures delay or stop the port activities, it may not only affect the trades of the country which located in the seismic region but also can cause problems all over the world. However, performance based design of port structures is still not well-known enough and it needs to be more investigations.

Researchers have focused on seismic performance of waterfront structures for a decade and reliable studies have been carried out both experimentally and numerically. It is very important to learn the lessons from past case studies to better understand the vulnerability of waterfront structures exposed to earthquake.

Experimental and analytical studies were carried out to investigate the dynamic behavior of gravity type quay walls by Miura et al. (2000), Fujiwara et al. (2000), Mohajeri et al. (2002), Mendez et al. (2009), Nakahara et al. (2004). Some of them were performed experimentally and/or numerically by Inoue et al. (2003), Kim et al. (2004), Kim et al. (2005), Towhata et al. (2009). The others were studied numerically by Alyami et al. (2009), Arablouei et al. (2011), Tiznado and Rodriguez Roa (2011). Most of these studies were conducted for caisson type quay walls. However, there is still lack of knowledge about seismic performance of block type quay walls.

This paper describes the earthquake resistant performance design of block type quay walls. Our major objective is to provide a determination method of the cross sections for verification of earthquake resistant performance using experimental results.

\section{EXPERIMENTAL STUDY}

The experimental study was conducted in a shaking tank at Hydraulic and Coastal Engineering Laboratory, Yıldız Technical University. The shaking tank has $4.5 \mathrm{~m}$ length, $1 \mathrm{~m}$ width and $1 \mathrm{~m}$ height (Fig. 1). The shaking tank was steered by PLC control. The properties of the control system have HSC (High speed counter) enter, pulse outlet, 1-10V analog outlet, I/0 8 enter, 8 outlet and 911 touch sensitive 16x106 colored operator panel. The amplitude range of the tank is $1-5 \mathrm{~mm}$ and the frequency range is $1-9 \mathrm{~Hz}$.

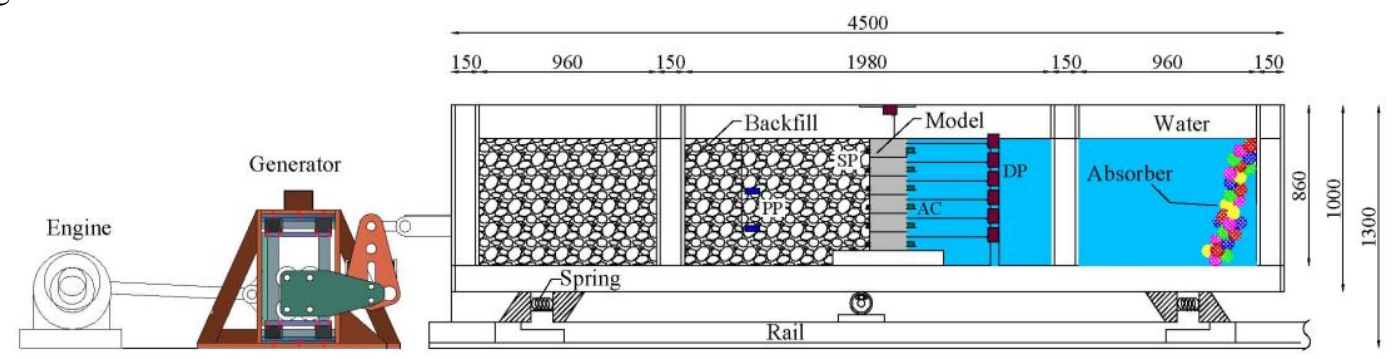

Figure 1. Longitudinal cross section of shaking tank.

Accelerometer, earth pressure transducer, pore water pressure transducer and displacement transducer were used in the experimental study and they were connected to the two data loggers (IMC brand) used to record the measured data to a personal computer to obtain the performance of block type quay wall models with varying block dimensions. The transducers were mounted on each model

\footnotetext{
${ }^{1}$ Project Company, MAG Engineering Services, Tugay Yolu Street (Ofisim İstanbul Plaza), İstanbul, 34865, Turkey

${ }^{2}$ Coastal \& Harbor Engineering, Yıldız Technical University, Davutpasa Campus, Esenler, 34220, Turkey
} 
block and after that, the backfill was poured behind the model wall by using pluviation device. The total mass of the backfill was $810 \mathrm{~kg}$.

Three different block type quay walls were considered for this paper which had different dimensions from each other (Fig. 2). First and second type walls (Type I \& II) had $10 \mathrm{~cm}$ heights for the blocks, while the third type wall (Type III) studied by Yuksel et al. (2011) had a block height of 20 $\mathrm{cm}$. However, the width of the blocks is $20 \mathrm{~cm}$ for the first type (Type I), $15 \mathrm{~cm}$ for the second type (Type II), and $30 \mathrm{~cm}$ for the third type (Type III).

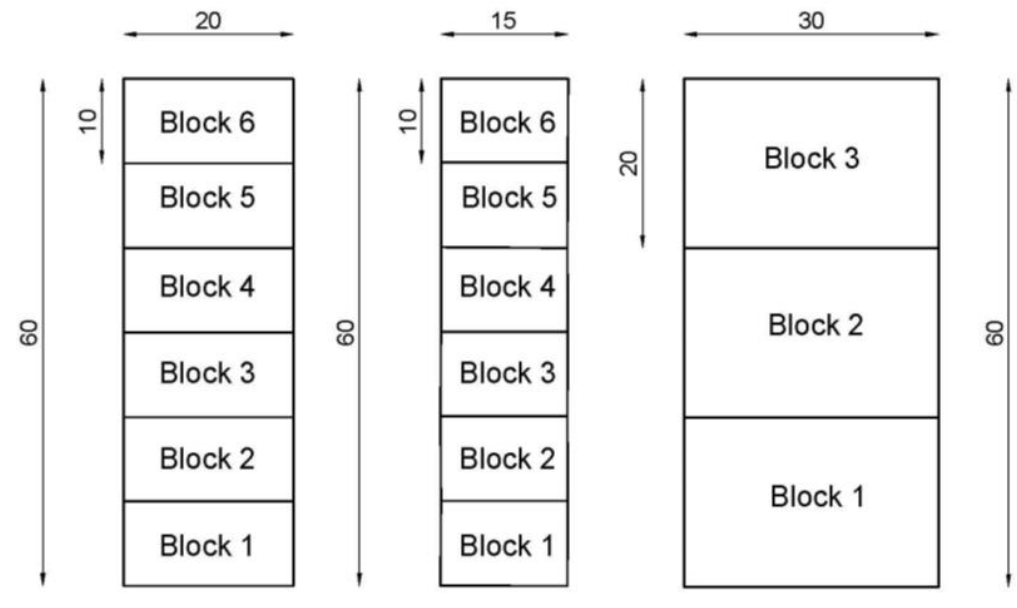

Figure 2. The dimensions in $\mathrm{cm}$ for the vertical walls (a) the first type vertical wall (Type I), (b) the second type vertical wall (Type II), (c) the third type vertical wall (Type III).

The water depth was constant which was considered as $60 \mathrm{~cm}$ in the shaking tank during the experiments. The relative density of the backfill was obtained as the same at each test by controlling the cap space and height of the bunker and the speed rate of the horizontal mobility of the bunker. The relative density of the backfill material was obtained as $70 \%$. In order to eliminate the liquefaction effect, the backfill and foundation soils were selected as gravel $\left(\mathrm{d}_{50}=0.8 \mathrm{~cm}\right)$ which is non liquefiable material (see Table 1 for detailed information of backfill properties).

\begin{tabular}{|l|c|}
\hline \multicolumn{1}{|c|}{ Table 1. The general properties of the backfill. } \\
\hline \multicolumn{1}{|c|}{ The parameters } & Values \\
\hline Void ratio, $(\mathrm{e})$ & 0.631 \\
\hline Porosity, $(\mathrm{n})$ & 0.386 \\
\hline Dry unit weight, $\left(\gamma_{\mathrm{k}}\right),\left(\mathrm{kN} / \mathrm{m}^{3}\right)$ & 16.413 \\
\hline Saturated unit weight, $\left(\gamma_{\mathrm{d}}\right),\left(\mathrm{kN} / \mathrm{m}^{3}\right)$ & 20.230 \\
\hline Specific gravity, $\left(\mathrm{G}_{\mathrm{s}}\right)$ & 2.73 \\
\hline Average grain diameter, $\left(\mathrm{D}_{50}\right),(\mathrm{cm})$ & 0.825 \\
\hline Effective grain diameter, $\left(\mathrm{D}_{10}\right),(\mathrm{cm})$ & 0.5 \\
\hline The uniformity coefficient, $\left(\mathrm{C}_{\mathrm{u}}\right)$ & 1.8 \\
\hline The gradation coefficient, $\left(\mathrm{C}_{\mathrm{c}}\right)$ & 1.08 \\
\hline
\end{tabular}

In this study, one-dimensional shaking responses were measured in the gravity type quay walls because quay walls are very long structures and seismic behavior is mainly two-dimensional. The quay walls were simulated by models with prototype ratio of $1 / 10$. Tests were performed on firm bottom condition and non-liquefiable backfill material to understand the behavior of the structure excluding the liquefaction effect. This work aimed at providing useful information for the design of block type quay walls constructed on firm seabed (non-liquefiable).The simulation of various parameters was in the $1 \mathrm{~g}$ gravitational field (see Iai, 1989) for soil-structure-fluid system adopted in this study is shown in Table 2. 


\begin{tabular}{|l|c|c|}
\hline \multicolumn{3}{|c|}{ Table 2. Similitude for the $\mathbf{1} \mathbf{g}$ field } \\
\hline \multicolumn{1}{|c|}{ Parameters } & Prototype/Model & Scale factor \\
\hline Length & $\lambda$ & 10 \\
\hline Time & $\lambda^{0.15}$ & 5.62 \\
\hline Acceleration & 1 & 1 \\
\hline Displacement & $\lambda^{1.5}$ & 31.62 \\
\hline Water Pressure & $\lambda$ & 10 \\
\hline Density & 1 & 1 \\
\hline Stress & $\lambda$ & 10 \\
\hline
\end{tabular}

The experiments were carried out under different sinusoidal harmonic waves and test conditions for each model walls are summarized in Table 3.

\begin{tabular}{|c|c|c|}
\hline \multicolumn{3}{|c|}{ Table 3. The experimental conditions } \\
\hline Test No & Wall Type & Base Acceleration $(\boldsymbol{g})$ \\
\hline 1 & \multirow{3}{*}{ Type I } & 0.058 \\
\hline 2 & & 0.083 \\
\cline { 1 - 1 } & & 0.184 \\
\hline 4 & \multirow{2}{*}{ Type II } & 0.344 \\
\hline 5 & & 0.066 \\
\hline 5 & \multirow{3}{*}{ Type III } & 0.074 \\
\hline 7 & & 0.226 \\
\hline 8 & & 0.356 \\
\hline 9 & & 0.494 \\
\hline
\end{tabular}

\section{RESULTS \& DISCUSSION}

To identify the performance of the gravity type quay structures, the parameters effective on this system have to be determined. The dimensional parameters are:

$$
F\left(\rho_{s}, d_{50}, H, B, \rho_{c}, \rho_{w}, a, g, D, h\right)=0
$$

where; $\mathrm{D}$ is the displacement, $\mathrm{B}$ is the block width, $\mathrm{H}$ is the wall height, $\rho_{\mathrm{c}}$ is the concrete density, $\rho_{\mathrm{s}}$ is soil density, $\rho_{\mathrm{w}}$ is water density, $\mathrm{d}_{50}$ is mean grain-size, a is acceleration, $\mathrm{g}$ is the gravitational acceleration, $\mathrm{h}$ is block height.

The dimensionless parameters have been determined by using dimensional analysis. In dimensional analysis, the performance of the gravity quay wall can be expressed as follows:

$$
\mathrm{f}\left(\frac{\mathrm{D}}{\mathrm{H}}, \frac{\mathrm{B}}{\mathrm{H}}, \frac{\rho_{\mathrm{c}}}{\rho_{\mathrm{s}}}, \frac{\rho_{\mathrm{w}}}{\rho_{\mathrm{s}}}, \frac{\mathrm{d}_{50}}{\mathrm{H}}, \frac{\mathrm{a}}{\mathrm{g}}, \frac{\mathrm{h}}{\mathrm{H}}\right)=0
$$

where $\mathrm{D} / \mathrm{H}$ is relative displacement, $\mathrm{B} / \mathrm{H}$ and $\mathrm{h} / \mathrm{H}$ is the ratio of the gravity wall dimensions, $\rho_{\mathrm{c}} / \rho_{\mathrm{s}}$ is the relative density, $\rho_{\mathrm{w}} / \rho_{\mathrm{s}}$ is the relative density, $\mathrm{d}_{50} / \mathrm{H}$ is the relative grain size, $\mathrm{a} / \mathrm{g}=\mathrm{a}(\mathrm{g})$ is seismic acceleration coefficient.

The dimensionless function can be reduced because both relative densities and relative grain size are constant.

$$
\mathrm{f}\left(\frac{\mathrm{D}}{\mathrm{H}}, \frac{\mathrm{B}}{\mathrm{H}}, \frac{\mathrm{D}}{\mathrm{B}}, \frac{\mathrm{a}}{\mathrm{g}}, \frac{\mathrm{h}}{\mathrm{H}}\right)=0
$$

In this study, three vertical block type quay walls with different block width and block height were modeled to investigate the dimension effect on the seismic stability. For this purpose, the experimental study was performed by using a shaking tank and different measurement devices (such as accelerometer, earth pressure, pore pressure and displacements transducers) were placed in the middle 
of each block except one of the accelerometer which was mounted on the shaking tank to determine each executed input motions. Profile measurement device was also used before and after shaking to obtain the amount of settlement of backfill material. However, in this paper just only acceleration and displacement results are presented.

The base accelerations in this study were performed as harmonic motions and an example view of a harmonic base acceleration is given in Fig. 3. The duration of the tests was almost $21 \mathrm{~s}$ for all type of model walls. The amplifications of each block were evaluated in accordance with acceleration data obtained for each block and the results shows that amplifications increased with increasing base accelerations from bottom to top. On the other hand, amplifications for Type I model wall are larger than the Type II model wall (see Fig. 4).

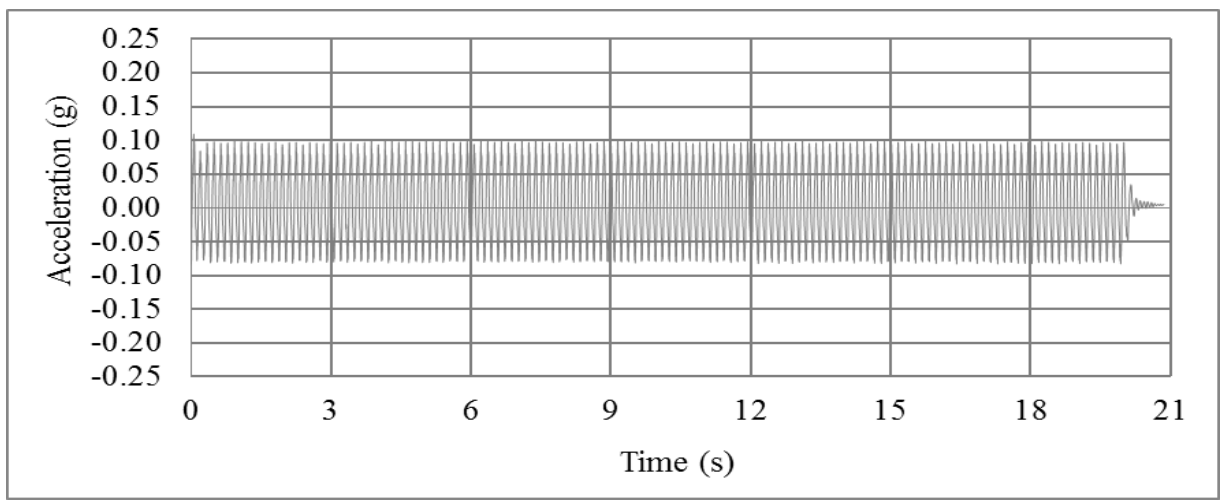

Figure 3. An example of harmonic base acceleration motion.

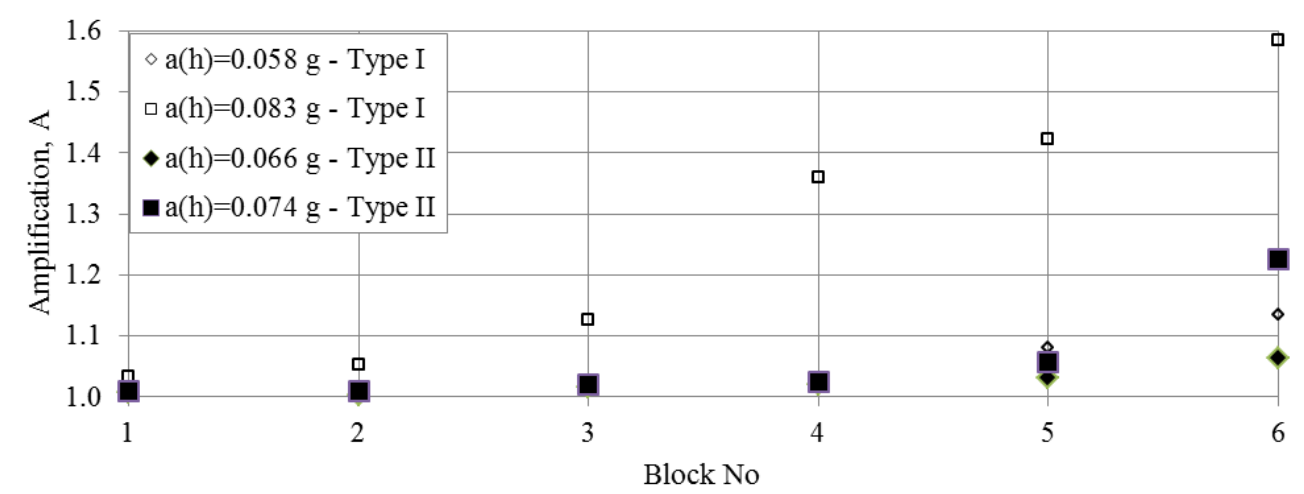

Figure 4. The amplification results for Type I and Type II model walls.

The variation of the normalized horizontal displacements versus base accelerations in $g$ (acceleration of gravity) was also analyzed respect to relative dimensions of the blocks for three type models. $D_{x}$ is identified as the horizontal displacement of each block, $\mathrm{z}$ is the vertical distance from crest to the middle of the blocks, $\mathrm{B}$ is the width of block, $\mathrm{h}$ is the height of the block and $\mathrm{H}$ is the total height of the gravity wall. The first examination is presented in Figs. 5 and 6 for the normalized horizontal displacements with respect to the ratio of $\mathrm{D}_{\mathrm{x}} / \mathrm{z}$. According to these results, the horizontal displacements are increased with increasing base acceleration from bottom to top similar to the amplifications, however, the comparative evaluations show that the normalized horizontal displacements for "Type I" are lower than "Type II" for given test conditions and this determination is in contrast to the relation of amplification results. Hence, the stability of this kind of quay walls may not just only controlled by amplifications and also effected by their friction surface. 


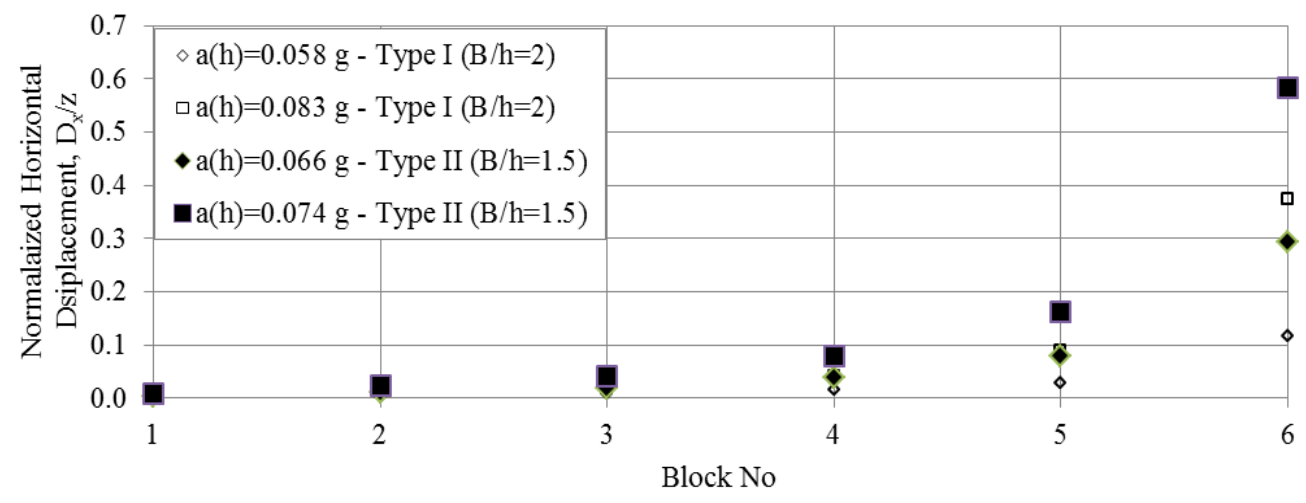

Figure 5. The normalized horizontal displacements $\left(D_{x} / z\right)$ for Type I and Type II model walls.

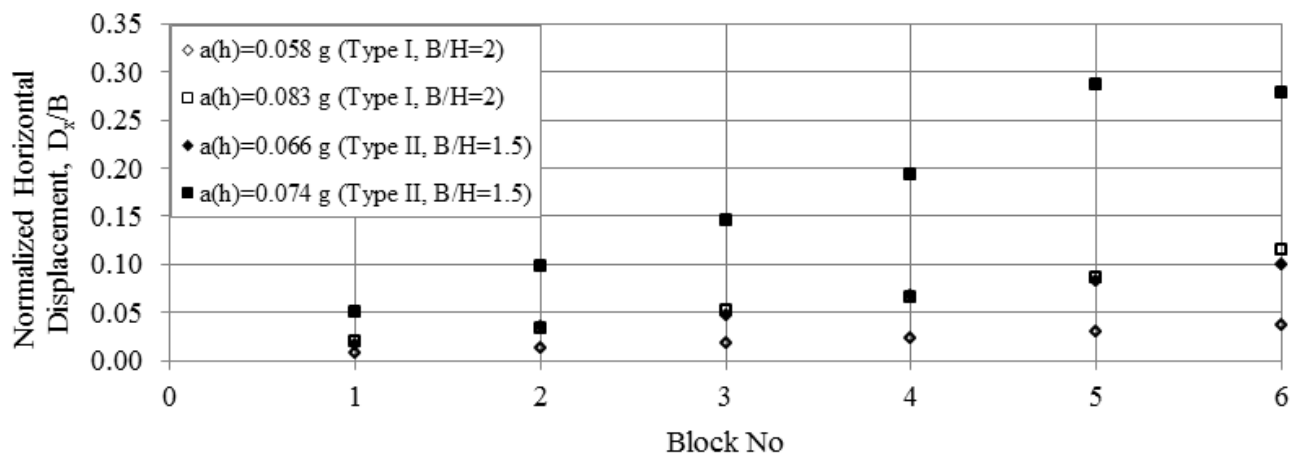

Figure 6. The normalized horizontal displacements $\left(D_{x} / B\right)$ for Type I and Type II model walls.

The block dimension effect on the stability of gravity walls is investigated with three different vertical block type quay wall models. These model walls have different block dimensions with same total wall heights. When the cross section of the model walls is considered (in Fig. 2), the ratios of $\mathrm{B} / \mathrm{h}=2,1.5$ and $1.5 \& \mathrm{H} / \mathrm{h}=6,6$ and 3 are obtained for Type I, II and III, respectively. The normalized horizontal displacements $\left(D_{x} / z\right)$ are also given for top blocks of these three different model walls versus different base accelerations in Fig. 7. The results enable to make comparisons for both ratios, separately. In light of this point of view, when the ratios of $\mathrm{B} / \mathrm{h}=1.5$ and 2.0 (with same $\mathrm{H} / \mathrm{h}=6$ ) compared, it can be seen that Type I wall model represented with diamond shaped points has smaller horizontal displacements than Type II wall model represented with triangular shaped points according to same base acceleration value. On the other hand, the comparison made for the ratios of $\mathrm{H} / \mathrm{h}=6.0$ and 3.0 (with same $\mathrm{B} / \mathrm{h}=1.5$ ) shows that Type III wall model's values represented with rectangular shaped points corresponds to larger base acceleration value than Type II model wall's values for a same amount of normalized horizontal displacement. Under these experimental conditions, it can be said that the ratio of the $\mathrm{B} / \mathrm{h}$ is not the only effective parameter; also the ratio of the $\mathrm{H} / \mathrm{h}$ is the important factor on the stability of the block type quay walls. 


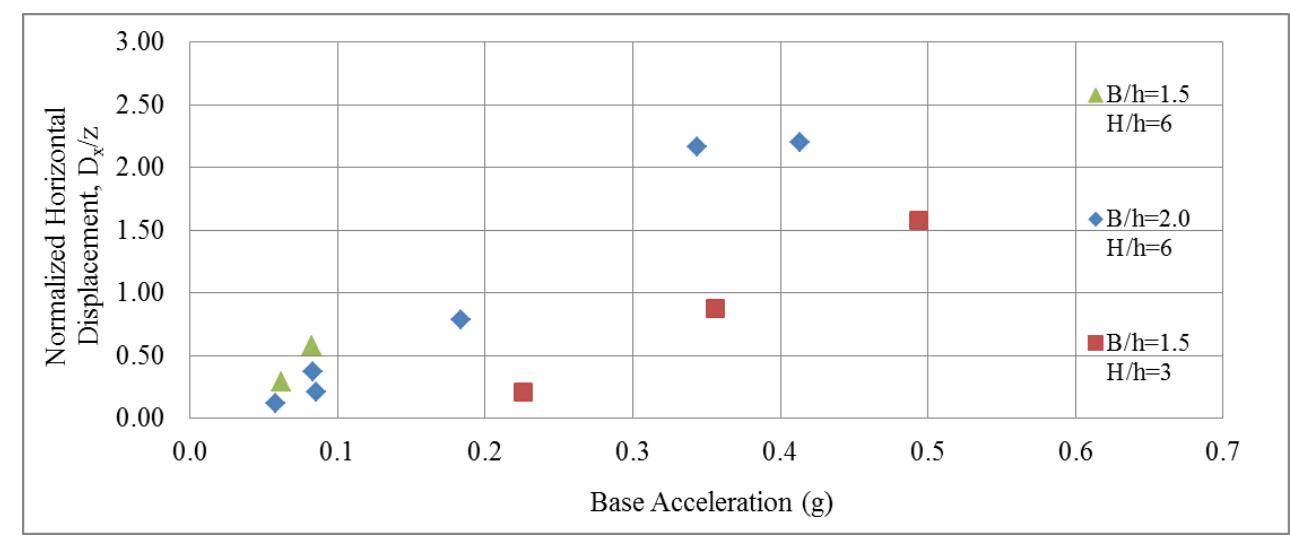

Figure 7. The normalized horizontal displacement $\left(D_{x} / z\right)$ results for Type I, II and III model walls

\section{CONCLUSION}

Block dimension for the block type quay walls is very important for the responses against the earthquake loadings. Most of the investigations and codes advise that the width should be two times of the gravity type quay height. However, this is not right enough because experimental and numerical investigations showed that geometry and the width/height ratio should be determined carefully. The optimum response dimensions show more resistance against the seismic loads because the increase of the block width caused the increase of the sliding resistance force as well as the increase of inertia force. In order to reduce sliding damage of block type quay walls, the block height should also increase relative to the total height of the wall.

\section{ACKNOWLEDGMENT}

The authors wish to express their sincere appreciation to TUBITAK for funding for research project no 113M426.

\section{REFERENCES}

Alyami, M., Rouainia, M and Wilkinson, S.M. 2009. Numerical Analysis of Deformation Behavior of Quay Walls under Earthquake Loading, Journal of Soil Dynamics and Earthquake Engineering, 29, 525-536.

Arablouei, A., Gharabaghi, A.R.M., Ghalandarzadeh, A., Abedi, K., Ishibashi, I. 2011. Effects of Seawater-Structure-Soil Interaction on Seismic Performance of Caisson Type Quay Wall, Computers and Structures, 89, 2439-2459.

Fujiwara, T., Horikoshi, K., Higuchi, Y. and Sueoka, T. 2000. Estimation of Dynamic Displacement of Gravity Type Quay Walls Based on Centrifuge Modelling, 12th World Conference on Earthquake Engineering, Japan.

Iai, S. 1989. Similitude for Shaking Table Tests on Soil-Structure-Fluid in $1 \mathrm{~g}$ Gravitational Field, Soils and Foundations, 29 (1), 105-118.

Kim, S.R., Kwon, O.S. and Kim, M.M. 2004. Evaluation of Force Components Acting on Gravity Type Quay Walls During Earthquakes, Journal of Soil Dynamics and Earthquake Engineering, 24, 853-866.

Mendez, B.C., Botero, E. and Romo, M.P. 2008. A New Friction Law for Sliding Rigid Blocks Under Cyclic Loadin, Soil Dynamics and Earthquake Engineering, 29 ,874-882.

Miura, K., Kohama, E., Inoue, K., Otsuka, N., Sasajima, T., Hayashi, T. and Yoshida, N. 2000. Behaviour of Gravity Type Quay Wall During Earthquake Regarding Dynamic Interaction Between Qaisson and Backfill During Liquefaction, 12th World Conference on Earthquake Engineering, Japan.

Mohajeri, M., Ichii, K. and Tamura, T. 2002. Modification of the Sliding Block Concept for Caisson Walls, Journal of Waterway, Port, Coastal and Ocean Engineering, ASCE, 134-142.

Nakahara, T., Kohama, E. and Sugano, T. 2004. Model Shake Table Test on the Seismic Performance of Gravity Type Quay Wall with Different Foundation Ground Properties, 13th World Conference on Earthquake Engineering, Canada. 
Tiznado, J.C. and Rodriguez-Roa, F. 2011. Seismic Lateral Movement Prediction for Gravity Retaining Walls on Granular Soils, Soil Dynamics and Earthquake Engineering, 31, 391-400.

Towhata, I., Alam, M.J., Honda, T. and Tamate, S. 2009. Model Tests on Behavior of Gravity Type Quay Walls Subjected to Strong Shaking, Bulletin of The New Zealand Society for Earthquake Engineering, 42(1), 47-56.

Yuksel,Y., Ergin, A., Yalciner, A. C., Berilgen, M., Cihan, K., Karakus, H., and Ulasan, A. 2011. Design of Block Type Quay Walls under Dynamic Loading using Simplified Method, Research Report supported by TUBITAK, report no: 111 Y006 (in Turkish). 